\title{
Long noncoding RNAs: functions and mechanisms in colon cancer
}

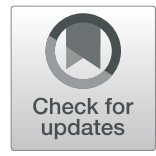

\author{
Sian Chen and Xian Shen*
}

\begin{abstract}
Evidence indicates that long non-coding RNAs (IncRNAs) play a crucial role in the carcinogenesis and progression of a wide variety of human malignancies including colon cancer. In this review, we describe the functions and mechanisms of IncRNAs involved in colon oncogenesis, such as HOTAIR, PVT1, H19, MALAT1, SNHG1, SNHG7, SNHG15, TUG1, XIST, ROR and ZEB1-AS1. We summarize the roles of IncRNAs in regulating cell proliferation, cell apoptotic death, the cell cycle, cell migrative and invasive ability, epithelial-mesenchymal transition (EMT), cancer stem cells and drug resistance in colon cancer. In addition, we briefly highlight the functions of circRNAs in colon tumorigenesis and progression, including circPPP1R12A, circPIP5K1A, circCTIC1, circ_0001313, circRNA_104916 and circRNA-ACAP2. This review provides the rationale for anticancer therapy via modulation of IncRNAs and circular RNAs (circRNAs) in colon carcinoma.
\end{abstract}

Keywords: LncRNAs, Colon cancer, miRNAs, Proliferation, Therapy

\section{Introduction}

Colon cancer is one of the most commonly diagnosed digestive cancers worldwide. In America, colon cancer has the fourth highest incidence behind breast, lung and prostate cancers, and is the second leading cause of death after lung cancer [1]. It is estimated that there are more than 1.5 million patients with colorectal cancer (CRC) in America, and 104,610 new cases will be expected in 2020 [1, 2]. In China, CRC is one of the top five diagnosed cancers and causes of cancer-related deaths [3]. Widespread colonoscopy testing has reduced the incidence rate of CRC. Due to improvements in treatments, including colectomy, chemotherapy and immunotherapy, the overall 5 -year relative survival rate for colon cancer patients is approximately 64\% [2]. Although diet, microorganisms and their metabolites are associated with colon carcinogenesis, the detailed mechanisms of CRC development remain unclear [4].

\footnotetext{
* Correspondence: shenxianwmu@126.com

Department of Gastrointestinal Surgery, the Second Affiliated Hospital of Wenzhou Medical University, No 109 Xueyuan West Road, Wenzhou, Zhejiang 325027, China
}

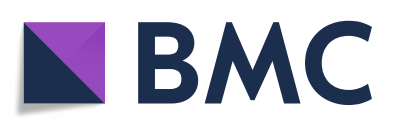

(c) The Author(s). 2020 Open Access This article is licensed under a Creative Commons Attribution 4.0 International License, which permits use, sharing, adaptation, distribution and reproduction in any medium or format, as long as you give appropriate credit to the original author(s) and the source, provide a link to the Creative Commons licence, and indicate if changes were made. The images or other third party material in this article are included in the article's Creative Commons licence, unless indicated otherwise in a credit line to the material. If material is not included in the article's Creative Commons licence and your intended use is not permitted by statutory regulation or exceeds the permitted use, you will need to obtain permission directly from the copyright holder. To view a copy of this licence, visit http://creativecommons.org/licenses/by/4.0/ The Creative Commons Public Domain Dedication waiver (http://creativecommons.org/publicdomain/zero/1.0/) applies to the data made available in this article, unless otherwise stated in a credit line to the data.
Therefore, elucidating the molecular mechanisms of colon oncogenesis is of crucial importance.

In recent years, noncoding RNAs (ncRNAs) have been demonstrated to be involved in colon cancer development and progression [5, 6]. It is well known that ncRNAs belong to a class of transcripts that are mostly translated into proteins, but they also play important roles in a variety of cellular and physiologic processes [7]. Long non-coding RNAs (LncRNAs) with a length longer than 200 nucleotides participates in multiple biological processes, including cell proliferation, differentiation, development, apoptosis and metastasis, often by serving as a competing endogenous RNA (ceRNA) to regulate the expression of specific miRNAs, and then target molecules downstream of these miRNAs [8]. In fact, lncRNAs can interact with RNA, DNA and protein, and form RNA-RNA, RNA-DNA, RNA-protein complexes, leading to regulation of gene expression via multiple mechanisms, including modulation of transcription, mRNA stability and translation $[9,10]$. LncRNAs can act as a guide, scaffolds or decoy molecule of proteins to recruit proteins or RNAs. LncRNAs can also affect the 
structure of chromatin and lead to modulating gene expression [11]. In addition, circular RNAs (circRNAs) belong to a new type of ncRNA with a circular configuration and are involved in carcinogenesis [12]. CircRNAs can not only act as sponges for miRNAs and RNA binding proteins, but also serve as mRNA transcriptional regulators and templates for protein translation [13-15]. LncRNAs and circRNAs have been revealed to be associated with the development and progression of a variety of human malignancies including colon cancer $[5,6,16]$. In this review, we will summarize the functions and mechanisms of lncRNAs and circRNAs in human colon oncogenesis and malignant progression.

\section{Role of IncRNAs in colon cancer}

Emerging evidence has implicated that lncRNAs play vital roles in colon carcinogenesis and progression [17, 18], with one study identifying approximately 200 differentially expressed lncRNAs in colon tumors using RNA sequencing data from TCGA dataset [19]. LncRNAs are involved in patient outcome [20], cell proliferation, [21], cell apoptosis [22], cell metastasis and invasion [23], cell cycle [24], epithelial-mesenchymal transition (EMT), cancer stem cells (CSCs) and drug resistance (Fig. 1). In the following section, we will describe the roles of lncRNAs in regulating these cellular processes and highlight the involved molecular mechanisms of lncRNAs (Table 1).

\section{LncRNAs are associated with patient outcomes}

Aberrant expression of lncRNAs has been reported to be correlated with the clinicopathological parameters of colon cancer [84]. For example, lncRNA zinc finger Ebox-binding homeobox 1 antisense 1 (ZEB1-AS1) expression is significantly elevated in colon adenocarcinoma tissues, which is consistent with data from TCGA database set [20]. Higher ZEB1-AS1 expression is observed in colon adenocarcinoma cell lines, including SW480, HT29, LS174T, HCT116 and DLD-1, when compared with normal colon histiocytes [20]. Increased ZEB1-AS1 is associated with an advanced stage, lymph node metastasis and distant metastasis in colon cancer patients. Moreover, patients with ZEB1-AS1 upregulation have poor survival [20]. FAM83H-AS1, one of dysregulated lncRNAs in several cancers, was shown to be highly expressed in colon cancer patients by RNAscope in situ hybridization analysis, and is associated with shorter overall survival time [41]. Moreover, FAM83HAS1 was observed to be negatively correlated with Smad1/5/9 levels, key factors in TGF- $\beta$ signaling, in colon cancer specimens [41]. The results of this study indicate that FAM83H-AS1 functions in part via the regulation of TGF- $\beta$ signaling in colon cancer [41]. High LINC01296 expression has been observed in colon cancer tumor tissues, which is also correlated with advanced Dukes' stage, poor prognosis and shorter survival rate [85]. Similarly, LINC01234 was reported to be highly expressed in colon cancer tissues, and colon cancer patients with upregulated LINC01234 have a shorter survival time [53]. ENST00000455974 expression is correlated with TNM stage and distant metastasis in colon cancer with DNA mismatch repair-proficient. Moreover, ENST00000455974 levels increase in the progression from normal colon, adenoma, carcinoma, and metastatic colon cancer tissues. Furthermore, higher expression of ENST00000455974 is related with shorter survival time in colon cancer patients [39]. Prostate cancer-associated ncRNA transcript 6 (PCAT6) is overexpressed in colon cancer tissues and is associated with advanced clinical stages and a worse prognosis [22].

Cytoskeleton regulator RNA (CYTOR), also named Linc00152, is upregulated in colon cancer patients and may be a predictive factor of a worse prognosis [34, 35].

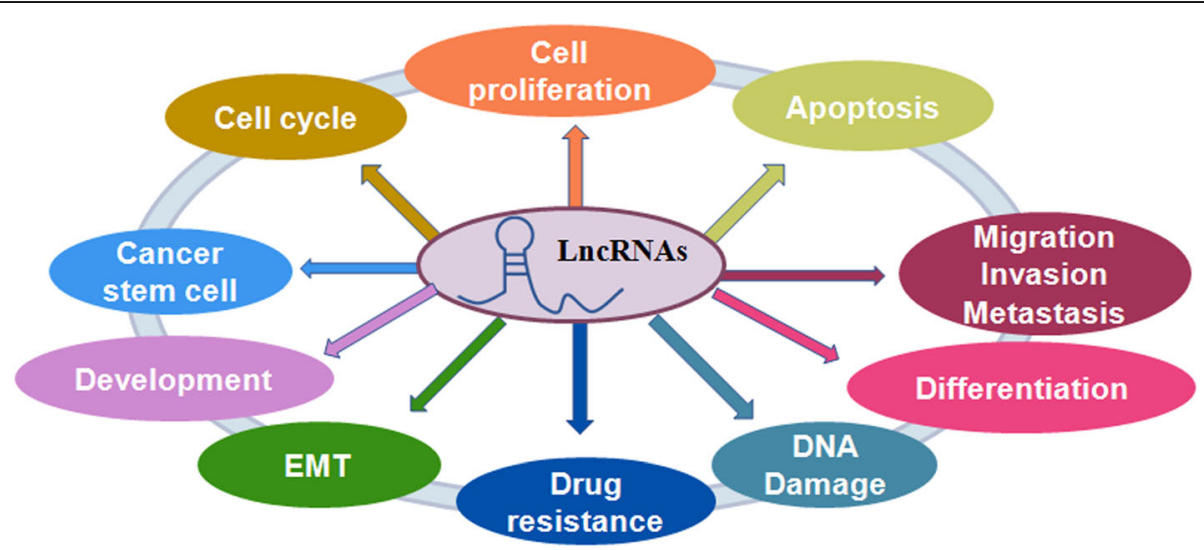

Fig. 1 The role of IncRNAs in regulating cellular processes. LncRNAs play a critical role in the regulation of cell proliferation, cell apoptotic death, cell cycle, cell migration and invasion, epithelial-mesenchymal transition (EMT), cancer stem cells, DNA damage and drug resistance in colon cancer 
Table 1 Representative IncRNAs and related signaling pathways in colon cance

\begin{tabular}{|c|c|c|c|c|}
\hline IncRNA & Expression & Functions & Downstream targets & References \\
\hline$\overline{\text { ATB }}$ & $\uparrow$ & Enhances invasion, induces EMT & $\begin{array}{l}\text { E-cadherin, ZO-1, ZEB1, N- } \\
\text { cadherin }\end{array}$ & {$[25]$} \\
\hline BC200 & $\uparrow$ & $\begin{array}{l}\text { Increases proliferation, invasion, EMT, inhibits apoptosis, regulates } \\
\text { cell cycle }\end{array}$ & STAT3, $\beta$-catenin & {$[24]$} \\
\hline B3GALT5-AS1 & $\downarrow$ & Inhibits proliferation, promotes migration, invasion, induces EMT & miR-203, ZEB2, Snail & {$[26]$} \\
\hline CASC15 & $\uparrow$ & Promotes proliferation, migration, invasion & miR-4310, LGR5, Wnt/ß-catenin & {$[27]$} \\
\hline CASC19 & $\uparrow$ & Increases migration & N/A & {$[28]$} \\
\hline CCAT1 & $\uparrow$ & $\begin{array}{l}\text { Promotes proliferation, } \\
\text { invasion, drug resistance }\end{array}$ & c-Myc & [29-31] \\
\hline CCAT2 & $\uparrow$ & Enhances growth, metastasis & miR-145, WNT & {$[32,33]$} \\
\hline CYTOR & $\uparrow$ & $\begin{array}{l}\text { Promotes migration, } \\
\text { invasion, EMT }\end{array}$ & $\beta$-catenin/TCF complex, & {$[34,35]$} \\
\hline DACOR1 & $\downarrow$ & Inhibits proliferation, increases DNA methylation & Cystathionine $\beta$-synthase & {$[36,37]$} \\
\hline DMTF1v4 & $\uparrow$ & Increases proliferation, migration, inhibits apoptosis & p-ERK, p-JNK, p-p38 & {$[38]$} \\
\hline ENST00000455974 & $\uparrow$ & $\begin{array}{l}\text { Increases proliferation, } \\
\text { migration }\end{array}$ & $J A G 2$ & [39] \\
\hline FAL1 & $\uparrow$ & $\begin{array}{l}\text { Enhances proliferation, } \\
\text { invasion, Inhibits apoptosis }\end{array}$ & STAT3, TGF- $\beta 1$, BCl-2, p65, PCNA & {$[40]$} \\
\hline FAM83H-AS1 & $\uparrow$ & Promotes tumorigenesis & TGF- $\beta$ signaling & [41] \\
\hline FER1L4 & $\downarrow$ & $\begin{array}{l}\text { Inhibits proliferation, } \\
\text { migration, invasion }\end{array}$ & miR-106a-5p & {$[42]$} \\
\hline GSEC & $\uparrow$ & Promotes migration & DHX36 & {$[43]$} \\
\hline HNF1A-AS1 & $\uparrow$ & $\begin{array}{l}\text { Enhances proliferation, } \\
\text { migration, invasion }\end{array}$ & miR-34a/p53 & [44] \\
\hline HOTAIR & $\uparrow$ & Increases migration, invasion & E-cadherin, vimentin, MMP-9 & {$[45-47]$} \\
\hline HULC & $\uparrow$ & Promotes proliferation, migration, invasion & $\begin{array}{l}\text { miR-613, RTKN, vimentin, N- } \\
\text { cadherin, E-cadherin }\end{array}$ & [48] \\
\hline $\mathrm{H} 19$ & $\uparrow$ & Enhances invasion, migration, drug resistance & miR138, HMGA1, miR-675-5p & {$[49,50]$} \\
\hline Linc00973 & / & Involves in drug resistance & N/A & {$[51]$} \\
\hline Linc01106 & $\uparrow$ & Confers proliferation, migration, stemness & miR-449b-5p, Gli & {$[52]$} \\
\hline Linc01234 & $\uparrow$ & Promotes proliferation & miR-642a-5p, SHMT2 & {$[53]$} \\
\hline Linc01567 & $\uparrow$ & Promotes proliferation, invasion, migration & miR-93 & {$[54]$} \\
\hline Linc00261 & $\downarrow$ & $\begin{array}{l}\text { Inhibits proliferation, invasion, migration, drug resistance, induces } \\
\text { apoptosis. }\end{array}$ & $\beta$-catenin, Wnt pathway & [55] \\
\hline Linc00657 & $\downarrow$ & Inhibits proliferation, invasion, induces apoptosis & CAPN7, PI3K/Akt & [56] \\
\hline Linc01082 & $\downarrow$ & Represses proliferation, migration, Invasion & / & {$[21]$} \\
\hline Linc01578 & $\uparrow$ & Enhances metastasis & NF-KB, YY1 & {$[57]$} \\
\hline Linc02418 & $\uparrow$ & Promotes growth, mobility, invasion, inhibits apoptosis & miR-34b-5p, Bcl-2 & {$[58]$} \\
\hline Lnc34a & $\uparrow$ & Enhances proliferation, stem cells & Dnmt3a, PHB2,HDAC1 & [59] \\
\hline Loc285194 & $\downarrow$ & Inhibits proliferation & miR-211 & {$[60]$} \\
\hline Loc441461 & $\uparrow$ & Increases growth, motility, inhibits apoptosis & PhoA, ROCK & {$[61]$} \\
\hline LincDUSP & $\uparrow$ & $\begin{array}{l}\text { Promotes proliferation, stem cells, modulates DNA damage } \\
\text { response and cell cycle, inhibits apoptosis }\end{array}$ & ATR, p53, E2F, c-Myc & [19] \\
\hline MALAT1 & $\uparrow$ & Enhances proliferation, invasion, migration & $\begin{array}{l}\text { miR-129-5p, HMGB1, } \\
\text { miR-663a }\end{array}$ & {$[62-64]$} \\
\hline MYU & $\uparrow$ & Increases proliferation, controls cell cycle & hnRNP-K, CDK6 & {$[65]$} \\
\hline PCAT6 & $\uparrow$ & Promotes proliferation, induces apoptosis & $\mathrm{EZH} 2, \mathrm{H} 3 \mathrm{~K} 4 \mathrm{me} 3$ & {$[22]$} \\
\hline Pint & $\downarrow$ & Inhibits proliferation & PRC2 & [66] \\
\hline
\end{tabular}


Table 1 Representative IncRNAs and related signaling pathways in colon cancer (Continued)

\begin{tabular}{|c|c|c|c|c|}
\hline IncRNA & Expression & Functions & Downstream targets & References \\
\hline PVT1 & $\uparrow$ & Promotes proliferation, migration, invasion & miR-26b, miR-30d-5p/RUNX2 & {$[67,68]$} \\
\hline RBM5-AS1 & / & Promotes proliferation, maintains stem cells & WNT, $\beta$-catenin & [69] \\
\hline $\mathrm{ROR}$ & $\uparrow$ & $\begin{array}{l}\text { Enhances proliferation, } \\
\text { migration, invasion }\end{array}$ & miR-145 & [70] \\
\hline RP11-619 L19.2 & $\uparrow$ & Enhances proliferation, migration, invasion, EMT & miR-1271-5p, CD164 & [71] \\
\hline SnaR & $\uparrow$ & Promotes drug resistance & N/A & [72] \\
\hline SBDSP1 & $\uparrow$ & Promotes proliferation, migration, invasion, regulates cell cycle, & $\begin{array}{l}\text { p21, cyclin D1, Akt, ERK1/2, } \\
\text { STAT3 }\end{array}$ & {$[73,74]$} \\
\hline SNHG1 & $\uparrow$ & Increases proliferation, invasion, migration, inhibits apoptosis & Wnt/ $\beta$-catenin, c-Myc, cyclin D & [75] \\
\hline SNHG7 & $\uparrow$ & Increases proliferation, inhibits apoptosis & $\begin{array}{l}\text { miR-193b, } \\
\text { K-ras/ERK/cyclinD1 }\end{array}$ & [76] \\
\hline SNHG15 & $\uparrow$ & $\begin{array}{l}\text { Enhances proliferation, } \\
\text { migration }\end{array}$ & Slug & [77] \\
\hline SNHG17 & $\uparrow$ & Elevates proliferation, migration, invasion & miR-375, CBX3 & [78] \\
\hline TUG1 & $\uparrow$ & Promotes proliferation, migration, invasion, EMT, inhibits apoptosis, & $\begin{array}{l}\text { miR-26a-5p, MMP-14, VEGF, } \\
\text { MAPK, Hsp27 }\end{array}$ & {$[23,79]$} \\
\hline UPAT & $\uparrow$ & Promotes survival & UHRF1 & [80] \\
\hline USP2-AS1 & $\uparrow$ & Enhances proliferation, metastasis & Phosph-YAP & [81] \\
\hline XIST & $\uparrow$ & Promotes proliferation & $\begin{array}{l}\text { miR-34a, Wnt, } \beta \text {-catenin cyclin } \\
\text { D1, c-Myc, MMP-7 }\end{array}$ & [82] \\
\hline ZEB1-AS1 & $\uparrow$ & Enhances proliferation, migration, invasion & miR-455-3p, PAK2 & [20] \\
\hline ZFAS1 & $\uparrow$ & $\begin{array}{l}\text { Increases proliferation, } \\
\text { invasion, EMT, inhibits apoptosis, }\end{array}$ & $\begin{array}{l}\text { ZEB1, E-cadherin, ZO-1, vimentin, } \\
\text { N-cadherin }\end{array}$ & [83] \\
\hline
\end{tabular}

CYTOR expression levels are correlated with TNM stage, disease-free survival and overall survival rates in patients with colon cancer [34]. LncRNA plasmacytoma variant translocation 1 (PVT1) expression is remarkably increased in colon cancer tissues and correlates with lymph node metastasis, clinical stages and survival time in patients with colon cancer [67]. Focally amplified lncRNA on chromosome 1 (FAL1) expression is strikingly increased in colon cancer specimens and is associated with a lower survival rate in colon cancer patients, indicating that FAL1 may be an independent prognostic factor in this disease [40]. Higher lncRNA BC200 expression was reported in colon tumor tissues and shown to be associated with TNM stage and lower survival time in patients with colon cancer [24]. Another lncRNA, HOTAIR, was observed to be highly expressed in colon cancer tissues and correlated with tumor invasion, metastasis, tumor stage and survival time [45-47]. The expression of lncRNA cancer susceptibility 15 (CASC15) is increased in colon tumor tissues and associates with TNM stage and tumor metastasis [27]. Small nucleolar RNA host gene 15 (SNHG15) is also upregulated in colon cancer patients and correlates with poor prognosis [77]. One group showed that lncRNA SBDSP1 is elevated in colon cancer tissues and further correlates with differentiation, invasion depth, TNM stage, and survival time in colon cancer patients [73]. LncRNA zinc finger antisense 1 (ZFAS1) is overexpressed in colon cancer specimens and correlates with TNM stage, vascular invasion and metastasis. Moreover, plasma of colon cancer patients has higher levels of ZFAS1 [83]. HNF1A-antisense 1 (HNF1A-AS1) expression is also higher in colon cancer tumors and correlates with advanced stage, metastasis and survival time in colon cancer patients [44].

LincRNA-ROR levels have been reported to be highly expressed in colon cancer tissues and are associated with tumor invasion and lymph node metastasis and AJCC stage in colon cancer patients [70]. LncRNA-activated by TGF-beta (lncRNA-ATB) expression is elevated in colon cancer tissues, especially in metastatic cancer specimens. LncRNA-ATB levels are associated with AJCC stage and survival time in patients with colon cancer [25]. In addition, IncRNA highly upregulated in liver cancer (HULC) is promoted in colon cancer tissues and correlates with clinicopathological parameters, including tumor stage, tumor size, metastasis and survival rate. CCAT1 expression has also been reported to be highly increased in colon cancer tissues and is associated with clinical stage, lymph nodes metastasis, and survival time [29]. Increased CASC19 expression is observed in colon cancer tissues and is associated with tumor size and metastasis [28]. Accumulating evidence has dissected that lncRNAs also perform antitumor activities in colon cancer. For example, B3GALT5-AS1 is decreased in colon 
tumor specimens, especially in liver metastasis tissues [26]. Moreover, lower expression of B3GALT5-AS1 levels is correlated with liver metastasis and poor outcome in colon cancer patients [26]. Similarly, LINC00657 expression is reduced in colon cancer patients, especially in patients with distant metastasis [56]. Lower LINC00657 expression is associated with TNM stage, tumor size and prognosis in colon cancer patients [56]. Fer-1-like protein 4. (FER1L4) levels are reduced in colon tumor specimens and is negatively associated with tumor invasion, metastasis and tumor stage, and colon cancer patients with lower FER1L4 expression have worse overall survival and disease-free survival rates [42].

\section{LncRNAs regulate cell proliferation}

Increasing evidence has revealed that IncRNAs play an important role in the regulation of cell proliferation. Multiple studies have clarified that lncRNA dysregulation is involved in governing colon cancer cell proliferation. ZEB1-AS1 overexpression facilitates cell growth by promoting p21-activated kinases 2 (PAK2) expression by sponging miR-455-3p in colon adenocarcinoma cells [20]. LINC01082 is downregulated in colon cancer tissues, and LINC01082 upregulation inhibits cell proliferation in SW480 and SW620 colon cancer cells [21]. LINC01296 silencing was found to suppress cell proliferation by targeting miR-21a in colon cancer cells [85]. Higher taurine-upregulated gene 1 (TUG1) expression has been reported in colon cancer tissues, and p63 downregulation increases TUG1 expression in HCT116 and LoVo colon cancer cells [79]. Moreover, knockdown of TUG1 suppresses the proliferation of HCT116 and LoVo cells [79]. Similarly, another study identified that knockdown of TUG1 blocks the proliferation of colon cancer cells, and impedes tumor growth in vivo [23]. Mechanistically, TUG1 overexpression elevates p-p38 mitogen-activated protein kinase (p-p38 MAPK), and pheat shock protein 27 (p-Hsp27) levels in colon cancer [23]. LncRNA small nucleolar RNA host gene 7 (SNHG7) is overexpressed in colon advanced adenomas and early-stage colon cancer, and SNHG7 downregulation in HT29 cells retards cell proliferation via interacting with miR-193b and suppressing K-ras/ERK/cyclin D1 [76]. Furthermore, LINC01234 enhances colon cancer cell proliferation via the upregulation of serine hydroxymethyltransferase 2 (SHMT2) by competitively binding with miR-642a-59 [53]. Downregulation of ENST00000455974 results in proliferation inhibition of colon cancer cells via the suppression of JAG2 [39]. PCAT6 was reported to increase cell growth by inhibiting colon cancer cell apoptosis [22]. Downregulation of HULC impairs colon cancer cell proliferation in vitro and retards tumor growth in mice by regulation of miR613/rhotekin (RTKN) [48].
LncRNA DMTF1v4 was reported to be overexpressed in colon cancer tissue, and DMTF1v4 knockdown in HT-29 cells suppresses cell proliferation via inhibition of p-ERK, p-JNK, and p-p38. Notably, knockdown of DMTF1v4 retards colon tumor growth in nude mice [38]. Studies have shown that PVT1 enhances cell growth via inhibiting miR-26b [68], while reduced PVT1 levels attenuates cell growth via regulation of the miR-30d-5p/RUNX2 axis [67]. One group identified that small nucleolar RNA host gene 1 (SNHG1) expression is overexpressed in colon cancer cells and tumor specimens. SNHG1 accelerates cell proliferation via upregulating $\beta$-catenin, $\mathrm{c}-\mathrm{Myc}$ and cyclin D1 protein levels in colon cancer cells [75]. In addition, metastasis associated lung adenocarcinoma transcript 1 (MALAT1) is highly expressed in several colon cancer cell lines such as LoVo, HCT116, SW480, and HT29 compared with normal intestinal epithelial HIEC cells. Downregulation of MALAT1 attenuates SW480 and HCT116 cell proliferation by acting a ceRNA to inhibit high motility group box protein 1 (HMGB1) via sponging miR-129$5 \mathrm{p}$ in colon cancer cells [62]. Similarly, another study also validated that MALAT1, which is highly expressed in colon cancer tissues, promotes SW480 and HCT116 colon cancer cell growth via binding miR-663a and upregulating several targets of miR-663, including TGF- $\beta 1$, PIK3CD, p53, p21, and JUND [63]. Zhang et al. demonstrated that inhibition of FAL1 suppresses cell proliferation, whereas FAL1 upregulation increases colon cancer cell proliferation. Mechanistically, FAL1 interacts with STAT3 and triggers its phosphorylation to modulate the expression of Bcl-2, TGF- $\beta 1$, p65, and PCNA in colon cancer cells [40]. Knockdown of lncRNA BC200 attenuates HCT-116 and HT29 colon cancer cell proliferation via downregulation of pSTAT3, Ki-67 and PCNA [24]. One study identified that B3GALT5-AS1 reduces colon cancer cell proliferation [26]. LncRNA XIST expression is increased in colon cancer tissues, while XIST silencing inhibits colon cancer cell growth and reduces tumor growth in vivo. Moreover, XIST can bind miR-34a and upregulate the expression of WNT1, $\beta$-catenin, cyclin D1, c-Myc and MMP-7 [82]. Upregulation of LINC00657 inhibits cell viability via promoting CAPN7 expression and suppressing the PI3K/Akt pathway in colon cancer cells [56].

In addition, CASC15 knockdown suppresses colon cancer cell proliferation and tumor growth in vitro and in vivo. Moreover, CASC15 serves as a sponge to inhibit miR-4310 and alter leucine-rich repeat-containing Gprotein coupled receptor 5 (LGR5) expression, leading to activation of the $\mathrm{Wnt} / \beta$-catenin signaling pathway [27]. Ectopic SNHG15 expression enhances tumor growth in a colon cancer xenografted model [77]. Downregulation of lincDUSP, an oncogenic lncRNA, inhibits the proliferation of patient-derived colon tumor cells [19]. LncRNA colon cancer-associated transcript-2 
(CCAT2) has been shown to harbor the rs6983267 SNP, which can regulate CCAT2 transcription. CCAT2 overexpression has been reported in CRC tissues [32]. Moreover, CCAT2 interacts with TCF7L2 and leads to WNT pathway activation, which subsequently enhances tumor growth and metastasis as well as chromosomal instability [32]. CCAT2 overexpression in HCT116 cells leads to promotion of xenograft tumor formation in nude mice [32]. CCAT2 has been shown to block the maturation of miR-145 by preventing pre-miR-145 export to the cytoplasm from nucleus, controlling colon cancer cell proliferation and differentiation [33]. Knockdown of CCAT2 suppresses HCT-116 cell proliferation, while CCAT2 overexpression facilitates the proliferation [33]. LINC00261 levels were reported to be decreased in colon cancer tissues, and upregulation of LINC00261 was shown to inhibit colon cancer cell viability by blocking $\beta$-catenin export to the nucleus from the cytoplasm or by promoting $\beta$-catenin degradation [55]. Moreover, ZFAS1 overexpression accelerates colon cancer cell proliferation [83]. Ectopic HNF1A-AS1 expression promotes colon cancer cell viability and tumor growth in vitro and in vivo. Moreover, HNF1A-AS1 silencing retards tumor growth in colon cancer xenograft models. Mechanistically, HNF1A-AS1 functions as a ceRNA to regulate miR-34a, consequently modulating SIRT1/p53 and activation of the Wnt signaling pathway [44]. Additionally, lincRNA-ROR downregulation in PKO colon cancer cells inhibits their proliferation [70]. Lnc34a has been shown to recruit Dnmt3a via PHB2 and HDAC1 to regulate miR-34a levels, leading to the promotion of CRC growth in xenograft mice. In agreement with this finding, Lnc34a is upregulated in late stage CRCs, leading to CRC cell proliferation [59]. FER1L4 overexpression inhibits the proliferation of colon cancer cells by acting as a ceRNA by sponging miR-106a-5p [42].

One study used RIP-sequenced and identified numerous lncRNAs that interact with DNMT1, a DNA methyl transferases, in HCT116 cells. Among these lncRNAs, DNMT1-associated colon cancer repressed lncRNA 1 (DACOR1) levels are decreased in colon tumors and cancer cell lines. Consistent with these findings, overexpression of DACOR1 decreased colony formation in colon cancer cells via activation of anticancer signaling pathways and inactivation of cancer-associated metabolic pathways [36]. Furthermore, c-Myc can promote CCAT1 transcription by directly binding to its promoter region. Ectopic CCAT1 expression stimulates cell proliferation in colon cancer cells [29]. Moreover, c-Myc directly binds to the promoter region of CCAT1 and enhances CCAT1 transcription [29]. One group characterized that lncRNA p53 induces noncoding transcript (Pint), which is governed by p53 pathway, facilitates cell proliferation and survival by modulating the TGF- $\beta$, MAPK and p53 pathways. Pint can interact with $\mathrm{PRC} 2$ and promotes H3K27 tri-methylation and repression [66]. LncRNA loc285194, a p53 transcript target, exhibits decreased expression in colon tumors, and its overexpression suppresses cancer cell growth in vitro and in vivo via inhibition of miR-211 [60]. LncRNA UPAT interacts with and stabilizes UHRF1 by blocking the $\beta$-transducin repeat-containing protein $(\beta-\operatorname{TrCP})$-induced ubiquitination of UHRF1 to promote Stearoyl-CoA desaturase 1 and Sprouty 4, of which is necessary to maintain colon cancer cell survival [80]. Taken together, these findings demonstrate that IncRNAs regulate cell proliferation in colon cancer cells.

\section{LncRNAs regulate cell apoptosis}

LncRNAs have been reported to govern cell apoptosis in colon cancer. In vitro and in vivo experiments have shown that PCAT6 inhibits cell apoptosis by promoting the enrichment of EZH2 and $\mathrm{H} 3 \mathrm{~K} 4 \mathrm{me} 3$ at the ARC region, leading to an increased ARC transcriptional activity in colon cancer cells [22]. The inhibition of SNHG7 in HT29 colon cancer cells stimulates cell apoptosis by inactivating K-ras/ERK/cyclin D1 signaling [76].

DMTF1v4 downregulation induces colon cancer cell apoptosis via upregulating the expression of apoptosisrelated proteins [38]. SNHG1 overexpression inhibits colon cancer cell apoptosis possibly via the Wnt/ $\beta$-catenin signaling pathway [75]. Downregulation of FAL1 in HT29 colon cancer cells stimulates cell apoptosis, indicating that FAL1 may inhibit cell apoptosis and increase cell proliferation in cells [40]. One group reported that silencing of $\mathrm{BC} 200$ stimulates the apoptosis of HCT-116 and HT29 colon cancer cells [24]. In addition, overexpression of LINC00657 increases cell apoptosis via inactivation of the PI3K/Akt pathway in colon cancer cells [56]. In another study, downregulation of lincDUSP was shown to induce the apoptosis of patient-derived colon cancer cells [19]. LINC00261 overexpression has been demonstrated to promote cell apoptosis [55], whereas lncRNA ZFAS1 impedes colon cancer cell apoptosis [83]. Moreover, the oncogenic lncRNA TUG1 inhibits the apoptosis of HCT116 and LoVo colon cancer cells [79].

\section{LncRNAs regulate invasion and metastasis}

LncRNAs have been shown to have crucial roles in regulating the migration, invasion and metastasis of colon cancer cells. ZEB1-AS1 facilitates cell invasion and migration via increasing PAK2 expression by sponging miR-455-3p, leading to the metastasis of colon cancer cells [20]. Upregulation of LINC01082 inhibits the migration and invasion of SW480 and SW620 colon cancer cells, indicating that LINC01082 has antitumor activity in colon cancer [21]. One study showed that LINC01296 downregulation retards the invasive activity of colon cancer cells by targeting miR-21a [85]. In addition, 
knockdown of TUG1 expression has been shown to attenuate the migration of HCT116 and LoVo colon cancer cells [79]. LncRNA HULC knockdown inhibits cell migration and invasion by modulating miR-613/RTKN expression in colon cancer cells [48]. Silencing of TUG1 impedes cell invasion in vitro and in mice via regulation of the miR-26a-5p/MMP14/p38 MAPK/Hsp27 axis [23]. Inhibition of ENST00000455974 causes disrupts the migration of colon cancer cells, whereas ENST00000455974 upregulation enhances the metastasis of colon cancer via the upregulation of JAG2 [39]. Downregulation of HULC attenuates the metastasis of colon cancer cells by interacting with miR-613 and modulating RTKN [48]. LncRNA DMTF1v4 overexpression enhances the migration of HT-29 cells via regulating the ERK/MAPK signaling pathway in colon cancer cells [38]. In another study, PVT1 was reported to enhance cell migration and invasion via the modulation of miR-26b and miR-30d-5p in colon cancer cells $[67,68]$.

One study demonstrated that inhibition of CYTOR retards the migration and invasion of colon cancer cells, while overexpression of CYTOR promotes colon cancer cell metastasis. Mechanistically, CYTOR enhances cell invasion and metastatic properties by interacting with $\beta$ catenin in colon cancer [34]. SNHG1 upregulation elevates cell migration and invasion via regulation of the $\mathrm{Wnt} / \beta$-catenin signaling pathway [75]. In vitro invasion assay results demonstrated that FAL1 increases the invasion in human colon cancer cells. Notably, FAL1 promotes cell invasion in part via modulation of $\mathrm{Bcl}-2$, TGF- $\beta 1$, p65, and PCNA expression in colon cancer cells [40]. Knockdown of BC200 blocks the invasion of HCT-116 and HT29 colon cancer cells via downregulation of MMP-2 and MMP-9 [24]. In another study, B3GALT5-AS1 was shown to increase colon cancer cell migration and invasion by binding to the miR-203 promoter and suppressing miR-203 expression. The results of an in vivo study also demonstrated that B3GALT5AS1 attenuates the liver metastasis of colon cancer cells via the repression of miR-203 [26]. In another study, LINC00657 overexpression was shown to increase invasive ability of colon cancer cells via targeting the PI3K/ Akt pathway and CAPN7 expression [56].

LncRNA MALAT1 activation promotes cell migration and invasion in SW480 and HCT116 cells by binding to miR-663a and promoting the activation of its targets [62]. Interestingly, one study reported that MALAT1 inhibits colon cancer cell migration and invasion via regulation of EpCAM and ITGB4. Moreover, PTEN controls MALAT1 expression via sponging several oncogenic miRNAs, including miR-17, miR-20a, and miR-106b [64]. In addition, CASC15 inhibition reduces the migration and invasion of colon cancer cells via regulation of the miR-4310/LGR5/Wnt/ $\beta$-catenin axis [27]. SNHG15 overexpression accelerates the migration of colon cancer cells via interaction with the Slug domain, which impairs the ubiquitination and degradation of Slug and maintains its stability in colon cancer [77]. LncRNA H19 is upregulated in colon cancer tissues, and its knockdown represses the migratory and invasive ability of colon cancer cells via sponging miR-138 and promoting the subsequent upregulation of high-mobility group A (HMGA1) [49]. LINC00261 upregulation attenuates colon cancer cell migrative and invasive ability via regulation the $\mathrm{WNT} / \beta$-catenin pathway [55]. Downregulation of CASC19 blocks the migratory ability of CRC cells, indicating that CASC19 may enhance CRC metastasis [28]. G-Quadruplex-forming sequence containing lncRNA (GSEC) was reported to be upregulated in colorectal cancer tissues, and its downregulation represses cell motility via suppressing DHX36 function in colon cancer [43]. LncRNA ZFAS1 promotes cell invasion in colon cancer cells [83]. Overexpression of HNF1A-AS1 increases colon cancer cell migration and invasion, while its downregulation attenuates tumor metastasis in colon cancer xenograft mice via regulation of the miR-34a/p53 signaling axis [44]. The downregulation of lincRNA-ROR in RKO colon cancer cells impedes their migratory and invasive ability by altering the activity of miR-145 [70]. LncRNA-ATB expression levels are higher in three highly invasive colon cancer cell lines, including Caco205, SW620 and Lovo cells than in the three poorly invasive cell lines SW480, Caco2 and HCT116 [25]. FER1L4 expression is decreased in colon cancer tissues and its overexpression impairs cell migration and invasion via downregulation of miR-106a-5p in colon cancer cells [42]. HOTAIR facilitates the migration and invasion of colon cancer cells in part via regulation of MMP-9 [46]. LncRNA CCAT1 increases cell invasion in colon cancer cells, which is regulated by c-Myc via binding to the CCAT1 promoter and activating its transcription [29]. Specifically, CCAT2overexpressing HCT116 cells exhibit liver metastasis in nude mice. Consistent with these results, CCAT2 knockdown attenuates the invasiveness of KM12SM colon cancer cells [32]. Silencing of SBDSP1 represses proliferation, migration, and invasion and induces G0/G1 cell cycle arrest via downregulation of p21, cyclin D1, Akt, ERK1/2, and STAT3 phosphorylation in colorectal cancer [74]. LncRNA SNHG17 elevates proliferation, migration, and invasion via serving as miR-375 sponge to control the expression of chromobox 3 (CBX3) in colon cancer [78]. Linc02418 promotes growth, mobility and invasion and inhibits apoptosis via targeting miR-34b-5p and Bcl-2 pathways in colon cancer [58]. LncRNA USP2-AS1 enhances cell proliferation and metastasis via downregulation of phosph-YAP in colon cancer [81]. LncRNA LOC441461 knockdown suppresses growth and induces apoptosis and represses motility via the inhibition of PhoA/ROCK pathways in colon cancer [61]. Linc01578 enhances tumor metastasis via modulation of NF-kB and Yin Yang 1 (YY1) axis in colon cancer [57]. 


\section{LncRNAs regulate the cell cycle}

LncRNAs have been revealed to control cell cycle of colon cancer cells. For instance, lncRNA BC200 silencing induces cell cycle arrest at G0/G1 phase, possibly by reducing the expression of cyclin D1, cyclin E, and cMyc through decreasing $\beta$-catenin levels [24]. Downregulation of lincDUSP induces cell cycle arrest at $\mathrm{S}$ phase in colon cancer cells potentially via regulation of cell cycle control pathways [19]. The levels of lncRNA MYU, a downstream target of c-Myc, are increased in most colon cancers and enhance the G1-S transition in the cell cycle process via its interaction with hnRNP-K and subsequent stabilization of CDK6 in colon cancer cells. Furthermore, lncRNA MYU promotes the proliferation and tumorigenicity of CRC cells [65].

\section{LncRNAs regulate cancer stem cells}

Emerging evidence has supported that CSCs play a crucial role in tumorigenesis, metastasis, recurrence and drug resistance. LncRNAs have been validated to participate in CSCs formation and maintenance in human cancers, including CRC. Lnc34a is overexpressed in colon CSCs and can trigger asymmetric division and promote the self-renewal of colon CSCs [59]. Increased IncRNA RBM5-AS1 expression is observed in colon cancer stemlike cells, with RBM5-AS1 promoting cell growth and survival via activation of the WNT signaling pathway through its interaction with $\beta$-catenin. Thus, RBM5-AS1 is important for the maintenance of colon CSCs [69]. Overexpression of CCAT2 increases the levels of multiple molecular markers of CSCs in colon cancer cells, indicating that CCAT2 may be involved in contributing to CSCs development [33]. LINC01567 (also known as LOCCS) is highly expressed in colon CSCs that express CD133+/CD166+/CD44+, and its inhibition suppresses the proliferation, migration, invasion and tumor xenografts of colon CSCs via sponging miR-93 [54]. Recently, linc01106 confers colon cancer proliferation, migration, and stemness via regulating the Gli family factors partly by sponging miR-449b-5p [52].

\section{LncRNAs regulates the EMT process}

EMT is a cellular process in which epithelial cells are changed to mesenchymal cells, providing them the ability to migrate and metastasize. Downregulation of TUG1 was shown to suppress EMT in part by targeting miR26a-5p and MMP-14, VEGF, MAPK and Hsp27 in colon cancer cells [23]. The results of this study suggest that TUG1 facilitates EMT in colon cancer cells. The loss of epithelial characteristics and the simultaneous gain of mesenchymal features are correlated with CYTOR expression, the upregulation of which triggers EMT in colon cancer cells [34]. Consistently, CYTOR expression is associated with the loss of epithelial features and the acquisition of mesenchymal characteristics in multiple colon cancer cell lines [34]. Importantly, BC200 downregulation inhibits EMT in HCT-116 and HT29 colon cancer cells in part via the suppression of STAT3 phosphorylation [24].

B3GALT5-AS1 induces EMT due to the suppression of miR-203 and the subsequent upregulation of miR-203 downstream targets such as ZEB2 and Snail2 in colon cancer cells, leading to colon cancer liver metastasis [26]. LncRNA ZFAS1 accelerates the EMT process via the induction of ZEB1 expression, while knockdown of ZFAS1 upregulates the expression of E-cadherin and $\mathrm{ZO}-1$, but decreases that of ZEB1, vimentin and $\mathrm{N}$ cadherin in colon cancer cells [83]. LncRNA-ATB downregulation enhances the expression of E-cadherin, ZO-1, while reducing that of ZEB1 and $\mathrm{N}$-cadherin ( $\mathrm{N}$-cad), and influences EMT in colon cancer cells [25]. Silencing HOTAIR elevates E-cadherin expression and suppresses that of vimentin and MMP-9, which can lead to EMT in colon cancer cells [46]. LncRNA HULC knockdown leads to a decrease in the expression of $\mathrm{N}$-cadherin and vimentin, and an increased E-cadherin expression [48], indicating that HULC may be involved in the EMT process in colon cancer cells. Recently, one study showed that downregulation of RP11-619L19.2 represses cell proliferation migration, invasion and EMT in colon cancer via targeting the miR-1271-5p/CD164 axis [71].

\section{LncRNAs regulate drug resistance}

Overcoming drug resistance is a major challenge for achieving better outcomes of cancer therapy and lncRNAs have been implicated in drug resistance development. Using RNA-Seq, RT-qPCR, bioinformatics, and murine tumor xenograft models, one group reported that the expression of five lincRNAs, including LINC00973, LINC00941, CASC19, CCAT1 and BCAR4, are consistently altered in HT-29 and HCT-116 cells after treatments with 5-FU, oxaliplatin and irinotecan both in vitro and in vivo. Among these five lincRNAs, LINC00973 is most strongly upregulated in colon cancer cells treated with 5FU, oxaliplatin, and irinotecan [51]. This report demonstrated that lncRNAs may participate in drug resistance in colon cancer. One study revealed that IncRNA CCAT1 is highly expressed in colon tumor specimens and colon cancer cell lines as well as 5-FU-resistent cells. CCAT1 overexpression in colon cancer cells reduces their sensitivity of 5-FU and promoted decreased apoptosis rates, whereas knockdown of CCAT1 leads to the opposite effects in colon cancer cells [30]. These results indicate that CCAT1 is involved in 5-FU resistance in colon cancer cells.

LncRNA H19 reduces vitamin D receptor (VDR) expression via miR-675-5p, while the VDR pathway also 
represses H19 expression via regulation of the c-Myc/ Mad-1 pathway. Notably, H19 overexpression stimulates resistance to $1,25(\mathrm{OH}) 2 \mathrm{D} 3$ treatment in colon cancer cells and mouse models [50]. LINC00261 downregulation is observed in cisplatin-resistant colon cancer cells, while LINC00261 upregulation reverses cisplatin resistance and enhances the cisplatin effects of this drug via inactivation of the $\beta$-catenin/WNT pathway [55]. CYTOR overexpression leads to resistance to oxaliplatin-induced apoptosis in colon cancer cells. CYTOR functions as a ceRNA to regulate miR-193a-3p expression and subsequently upregulates that of Erb-b2 receptor tyrosine kinase 4 (ERBB4). Inhibition of ERBB4 reduces pAkt levels and attenuates oxaliplatin resistance [35]. One study measured the expression pattern of 90 lncRNAs via qPCR-based profiling in colon cancer SNU-C4 and SNU-C5 cells with 5-FU-resistance and identified 19 differentially expressed lncRNAs and 23 lncRNAs in 5-FU-resistent-SNU-C4 and SNU-C5 cells, respectively, including the lncRNA snaR and BACE1AS. Moreover, inhibition of snaR increases cell sensitivity to 5FU treatment, indicating that snaR contributes to 5-FU resistance in colon cancer cells [72].

\section{LncRNAs are involved in DNA methylation and the DNA damage response}

DNA methylation has been shown to play a crucial role in chromatin organization and gene expression [86]. DNA methylation occurs in gene promoters, gene bodies and intergenic regions of the genome, and is important in regulating gene expression [86]. Downregulation of lincDUSP in colon cancer cells promotes S-phase accumulation and $\gamma \mathrm{H} 2 \mathrm{AX}$ foci formation, suggesting that lincDUSP is involved in inducing DNA damage response [19]. Overexpression of DACOR1 decreases cystathionine $\beta$-synthase expression and inhibits the production of S-adenylyl methionine, an important methyl donor for DNA methylation [36]. Therefore, DACOR1 contributes to aberrant DNA methylation and colon carcinogenesis [36]. Moreover, this group demonstrated that DACOR1 upregulation reprograms genome-wide DNA methylation in colon cancer cells, including gene promoters, gene bodies, and intergenic regions, leading to the inhibition of FOS and JUN and the repression of AP-1 activity in colon cancer cells [37].

\section{Role of circular RNA in colon cancer}

Circular RNAs (circRNAs) play essential roles in the development and progression of colon cancer (Table 2). The circRNA circPPP1R12A is highly expressed in colon cancer tissues and its overexpression in colon cancer patients is correlated with shorter overall survival [87]. In addition, the circPPP1R12A-73aa protein, encoded by circPPP1R12A, increases cell proliferation, migrative and invasive abilities via regulation of the Hippo-YAP signaling pathway in colon cancer cells [87]. CircPIP5K1A is overexpressed in colon cancer tissues. Reduced circPIP5K1A expression attenuates cell viability and reduces cell motility, while circPIP5K1A overexpression facilitates colon cancer cell migration and invasion. Mechanistically, enforced expression of circPIP5K1A increases AP-1 expression and alleviates that of CDX-2, Zic-1, and IRF-4 in colon cancer cells in part via the suppression of miR-1273a. Therefore, circPIP5K1A augments colon oncogenesis via inhibiting miR-1273a [88]. Higher circCTIC1 expression is observed in colon tumor tissues and TICs, which is associated with tumor prognosis. Inhibition of circCTIC1 represses the self-renewal of colon TICs, while its upregulation augments TIC self-renewal via c-Myc regulation [89]. Mechanistically, circCTIC1 may bind to the NURF complex, allowing it to bind the c-Myc promoter and activate c-Myc transcription, leading to the selfrenewal of TICs in colon cancer [89].

The expression of circ_0001313, also known as circCCDC66, is increased in typical and radio-resistant colon cancer tissues. In both SW480 and SW620 cells, circ_0001313 expression is increased after irradiation treatment. Circ_0001313 knockdown enhances the radio-sensitivity of colon cancer cells and inhibits their viability and colony formation rate via regulation of miR-338-3p level [90]. CircRNA_104916 is downregulated in CRC tissues and is negatively associated with tumor size, $\mathrm{T}$ state and metastasis, and is correlated with a better survival in CRC patients. CircRNA_104916 upregulation stimulates apoptosis and cell cycle arrest at G2/M phase due to apoptosis pathway activation and increased cyclin proteins levels in LoVo and Caco-2 cells. Moreover, circRNA_104916 upregulation alleviates migratory and invasive ability of colon cancer cells via EMT suppression [91].

The expression of circRNA-ACAP2 is higher in colon cancer tissues than in normal tissues, and its knockdown represses SW480 cell proliferation, migration and invasion via upregulation of miR-21-5p and further inhibition of Tiam1, a downstream target of miR-21-5p [92]. One group identified three circRNAs, including circ-CCDC66, circ-ABCC1 and circ-STIL, which are downregulated in the plasma of CRC patients. The level of circ-ABCC1 is associated with tumor growth and progression, and circCCDC66 and circ-ABCC1 levels are reduced in precursor lesions of $\mathrm{CRC}$, indicating that these lncRNAs may be biomarkers for early stage CRC. The use of two traditional biomarkers of CRC, CEA and CA19-9, in combination with these three lncRNAs improves the diagnostic precision of CRC. Moreover, these three lncRNAs are useful for diagnosing CEAnegative and CA 19-9-negative CRC [93]. Thus, these circRNAs participate in colon tumorigenesis and progression (Fig. 2). 
Table 2 Representative circRNAs and related signaling pathways in colon cancer

\begin{tabular}{lllll}
\hline Circular RNA & Expression & Functions & Downstream targets & References \\
\hline CircPPP1R12A & $\uparrow$ & Promotes tumorigenesis, Increases proliferation, migration, invasion & Hippo-YAP & miR-1273a, Zic-1, CDX-2, $\quad$ [88] \\
CircPIP5K1A & $\uparrow$ & Increases viability, migration, invasion & IRF-4 & c-Myc \\
CircCTIC1 & $\uparrow$ & Promotes tumorigenesis, self-renewal of stem cells & miR-338-3p \\
Circ_0001313 & $\uparrow$ & Enhances radioresistance & [89] \\
CircRNA_ & $\downarrow$ & Inhibits tumorigenesis, EMT, migration, invasion, induces apoptosis, controls & Apoptosis pathway, cyclin [91] \\
104916 & & cell cycle. & proteins & hsa-miR-21-5p, Tiam1 \\
CircRNA- & $\uparrow$ & Enhances proliferation, migration, invasion & [92] \\
ACAP2 & & & & \\
\hline
\end{tabular}

\section{Conclusions}

In summary, lncRNAs and circRNAs have emerged as playing crucial roles in the initiation and progression of colon cancer. Targeting these noncoding RNAs could be helpful to obtain treatment benefit in colon cancer patients. Several compounds have been identified to regulate the expression of IncRNAs in human colon cancer [51, 94, 95]. For instance, ginsenoside Rg3 reduces the expression of IncRNA CCAT1 in colorectal cancer Caco-2 cells, leading to suppression of cell growth, migration and invasion [94]. Two anticancer agents, 3,3'diindolylmethane and doxycycline, regulates several lncRNAs in HCT-116 and HT-29 colon cancer cells [51]. Different chemotherapeutic drugs, including 5fluorouracil, oxaliplatin and irinotecan, elevated the expression of linc00973 in colon cancer HT-29 and HCT-116 cells [95]. In addition, identification of a stool lncRNAs panel might be useful for early detection of colorectal cancer [96].

However, several important questions must be addressed to obtain a full understanding the functions of lncRNAs in colon carcinogenesis. For instance, because lncRNAs can be multi-functional in regulating several cellular processes in various tissues, detailed molecular mechanisms of lncRNA functions needs to be appreciated on a case-by-case basis. Furthermore, it is necessary to validate whether the reliability and sensitivity of lncRNAs are enough for their clinical application as biomarkers. CEA and CA19-9 have been used in clinical colon cancer diagnosis, but whether lncRNAs and

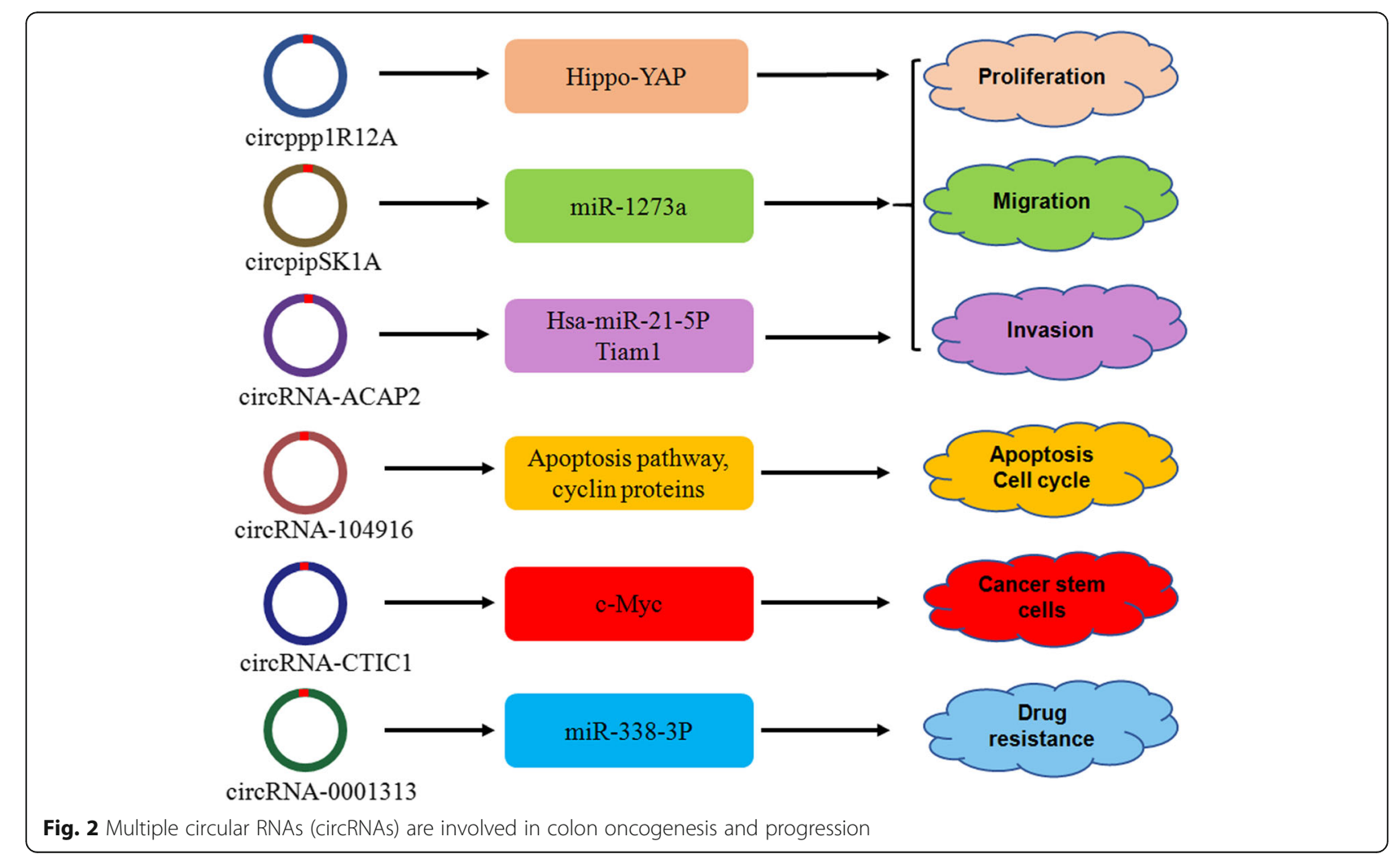


circRNAs have advantages compared these biomarkers need to be determined. We are optimistic that the use of new and robust sequencing technologies will elucidate roles of lncRNAs implicated in colon tumorigenesis may eventually accelerate the clinical application of lncRNAs for use in diagnosis, treatment, and prognosis evaluation.

\section{Abbreviations}

AP-1: Activator protein 1; CA19-9: Carbohydrate antigen 19-9; CDX-2: Caudal type homeobox 2; CEA: Carcinoembryonic antigen; DHX36: DEAH box polypeptide 36; GSEC: G-quadruplex-forming sequence containing IncRNA; IRF-4: Interferon regulating factor 4; PRC2: Polycomb repressive complex 2; Tiam1: T lymphoma invasion and metastasis protein 1; TICs: Tumor-initiating cells; UHRF1: Ubiquitin-like plant homeodomain (PHD) and really interesting new gene (RING) Finger domain containing protein 1; UPAT: UHRF1 protein associated transcript; Zic-1: Zinc finger of the cerebellum 1

\section{Acknowledgements}

Not applicable.

\section{Authors' contributions}

SC searched literature, made the figures and Tables. SC and XS wrote the manuscript. All authors read and approved the final manuscript.

\section{Funding}

Not applicable

\section{Availability of data and materials}

Not applicable.

\section{Ethics approval and consent to participate}

Not applicable.

\section{Consent for publication}

Not applicable.

\section{Competing interests}

The authors declare that they have no competing interests.

Received: 18 September 2020 Accepted: 20 November 2020

Published online: 28 November 2020

\section{References}

1. Siegel RL, Miller KD, Jemal A. Cancer statistics, 2020. CA Cancer J Clin. 2020; 70:7-30.

2. Miller $K D$, Nogueira L, Mariotto $A B$, Rowland JH, Yabroff KR, Alfano CM, Jemal A, Kramer JL, Siegel RL. Cancer treatment and survivorship statistics, 2019. CA Cancer J Clin. 2019;69:363-85.

3. Wu C, Li M, Meng H, Liu Y, Niu W, Zhou Y, Zhao R, Duan Y, Zeng Z, Li X, et al. Analysis of status and countermeasures of cancer incidence and mortality in China. Sci China Life Sci. 2019;62:640-7.

4. O'Keefe SJ. Diet, microorganisms and their metabolites, and colon cancer. Nat Rev Gastroenterol Hepatol. 2016;13:691-706.

5. Tang X, Qiao X, Chen C, Liu Y, Zhu J, Liu J. Regulation mechanism of long noncoding RNAs in Colon Cancer development and progression. Yonsei Med J. 2019;60:319-25.

6. Okayama H, Schetter AJ, Harris CC. MicroRNAs and inflammation in the pathogenesis and progression of colon cancer. Dig Dis. 2012;30(Suppl 2):9-15.

7. Guttman M, Amit I, Garber M, French C, Lin MF, Feldser D, Huarte M, Zuk O, Carey BW, Cassady JP, et al. Chromatin signature reveals over a thousand highly conserved large non-coding RNAs in mammals. Nature. 2009:458:223-7.

8. Bhan A, Mandal SS. Long noncoding RNAs: emerging stars in gene regulation, epigenetics and human disease. ChemMedChem. 2014;9:1932-56.

9. Gil N, Ulitsky I. Regulation of gene expression by cis-acting long non-coding RNAs. Nat Rev Genet. 2020;21:102-17.

10. Yao RW, Wang Y, Chen LL. Cellular functions of long noncoding RNAs. Nat Cell Biol. 2019;21:542-51.
11. Goodall GJ, Wickramasinghe VO. RNA in cancer. Nat Rev Cancer. 2020 https://doi.org/10.1038/s41568-020-00306-0. Online ahead of print.

12. Chen B, Huang S. Circular RNA: an emerging non-coding RNA as a regulator and biomarker in cancer. Cancer Lett. 2018:418:41-50.

13. Wang $Y$, Zhang Y, Wang P, Fu X, Lin W. Circular RNAs in renal cell carcinoma: implications for tumorigenesis, diagnosis, and therapy. Mol Cancer. 2020;19:149.

14. Chen LL. The expanding regulatory mechanisms and cellular functions of circular RNAs. Nat Rev Mol Cell Biol. 2020;21:475-90.

15. Kristensen LS, Andersen MS, Stagsted LWW, Ebbesen KK, Hansen TB, Kjems J. The biogenesis, biology and characterization of circular RNAs. Nat Rev Genet. 2019;20:675-91.

16. Hsiao KY, Sun HS, Tsai SJ. Circular RNA - new member of noncoding RNA with novel functions. Exp Biol Med (Maywood). 2017;242:1136-41.

17. Bhan A, Soleimani M, Mandal SS. Long noncoding RNA and Cancer: a new paradigm. Cancer Res. 2017;77:3965-81.

18. Deng H, Wang JM, Li M, Tang R, Tang K, Su Y, Hou Y, Zhang J. Long noncoding RNAs: new biomarkers for prognosis and diagnosis of colon cancer. Tumour Biol. 2017:39:1010428317706332.

19. Forrest ME, Saiakhova A, Beard L, Buchner DA, Scacheri PC, LaFramboise T, Markowitz S, Khalil AM. Colon Cancer-Upregulated long non-coding RNA lincDUSP regulates cell cycle genes and potentiates resistance to apoptosis. Sci Rep. 2018:8:7324

20. Ni X, Ding Y, Yuan H, Shao J, Yan Y, Guo R, Luan W, Xu M. Long non-coding RNA ZEB1-AS1 promotes colon adenocarcinoma malignant progression via miR-455-3p/PAK2 axis. Cell Prolif. 2020;53:e12723.

21. Xiong W, Qin J, Cai X, Xiong W, Liu Q, Li C, Ju Y, Wang Q, Li Y, Yang Y. Overexpression LINC01082 suppresses the proliferation, migration and invasion of colon cancer. Mol Cell Biochem. 2019;462:33-40.

22. Huang W, Su G, Huang X, Zou A, Wu J, Yang Y, Zhu Y, Liang S, Li D, Ma F, Guo L. Long noncoding RNA PCAT6 inhibits colon cancer cell apoptosis by regulating anti-apoptotic protein ARC expression via EZH2. Cell Cycle. 2019; 18:69-83.

23. Tian L, Zhao ZF, Xie L, Zhu JP. Taurine up-regulated 1 accelerates tumorigenesis of colon cancer by regulating miR-26a-5p/MMP14/p38 MAPK/Hsp27 axis in vitro and in vivo. Life Sci. 2019:239:117035.

24. Wu K, Xu K, Liu K, Huang J, Chen J, Zhang J, Zhang N. Long noncoding RNA BC200 regulates cell growth and invasion in colon cancer. Int J Biochem Cell Biol. 2018;99:219-25.

25. Yue B, Qiu S, Zhao S, Liu C, Zhang D, Yu F, Peng Z, Yan D. LncRNA-ATB mediated E-cadherin repression promotes the progression of colon cancer and predicts poor prognosis. J Gastroenterol Hepatol. 2016;31:595-603.

26. Wang L, Wei Z, Wu K, Dai W, Zhang C, Peng J, He Y. Long noncoding RNA B3GALT5-AS1 suppresses colon cancer liver metastasis via repressing microRNA-203. Aging (Albany NY). 2018;10:3662-82.

27. Jing N, Huang T, Guo H, Yang J, Li M, Chen Z, Zhang Y. LncRNA CASC15 promotes colon cancer cell proliferation and metastasis by regulating the miR4310/LGR5/Wnt/betacatenin signaling pathway. Mol Med Rep. 2018;18 2269-76.

28. Wang JJ, Li XM, He L, Zhong SZ, Peng YX, Ji N. Expression and function of long non-coding RNA CASC19 in colorectal Cancer. Zhongguo Yi Xue Ke Xue Yuan Xue Bao. 2017;39:756-61.

29. He X, Tan X, Wang X, Jin H, Liu L, Ma L, Yu H, Fan Z C-Myc-activated long noncoding RNA CCAT1 promotes colon cancer cell proliferation and invasion. Tumour Biol. 2014:35:12181-8.

30. Yang C, Pan Y, Deng SP. Downregulation of IncRNA CCAT1 enhances 5-fluorouracil sensitivity in human colon cancer cells. BMC Mol Cell Biol. 2019;20:9.

31. Kam Y, Rubinstein A, Naik S, Djavsarov I, Halle D, Ariel I, Gure AO, Stojadinovic A, Pan H, Tsivin V, et al. Detection of a long non-coding RNA (CCAT1) in living cells and human adenocarcinoma of colon tissues using FIT-PNA molecular beacons. Cancer Lett. 2014;352:90-6.

32. Ling H, Spizzo R, Atlasi Y, Nicoloso M, Shimizu M, Redis RS, Nishida N, Gafa R, Song J, Guo Z, et al. CCAT2, a novel noncoding RNA mapping to 8q24, underlies metastatic progression and chromosomal instability in colon cancer. Genome Res. 2013;23:1446-61.

33. Yu Y, Nangia-Makker P, Farhana L, Majumdar APN. A novel mechanism of IncRNA and miRNA interaction: CCAT2 regulates miR-145 expression by suppressing its maturation process in colon cancer cells. Mol Cancer. 2017:16:155.

34. Yue B, Liu C, Sun H, Liu M, Song C, Cui R, Qiu S, Zhong M. A positive feedforward loop between LncRNA-CYTOR and Wnt/beta-catenin signaling promotes metastasis of Colon Cancer. Mol Ther. 2018;26:1287-98. 
35. Yue B, Cai D, Liu C, Fang C, Yan D. Linc00152 functions as a competing endogenous RNA to confer Oxaliplatin resistance and holds prognostic values in Colon Cancer. Mol Ther. 2016;24:2064-77.

36. Merry CR, Forrest ME, Sabers JN, Beard L, Gao XH, Hatzoglou M, Jackson MW, Wang Z, Markowitz SD, Khalil AM. DNMT1-associated long non-coding RNAs regulate global gene expression and DNA methylation in colon cancer. Hum Mol Genet. 2015;24:6240-53.

37. Somasundaram S, Forrest ME, Moinova H, Cohen A, Varadan V, LaFramboise T, Markowitz S, Khalil AM. The DNMT1-associated lincRNA DACOR1 reprograms genome-wide DNA methylation in colon cancer. Clin Epigenetics. 2018;10:127.

38. Zhuang ST, Cai YJ, Gao HC, Qiu JF, Zeng L, Zheng WJ. Study on the function and mechanism of long non-coding RNA DMTF1v4 in the occurrence of colon cancer. Eur Rev Med Pharmacol Sci. 2018;22:3779-88.

39. Lao Y, Li Q, Li N, Liu H, Liu K, Jiang G, Wei N, Wang C, Wang Y, Wu J. Long noncoding RNA ENST00000455974 plays an oncogenic role through upregulating JAG2 in human DNA mismatch repair-proficient colon cancer. Biochem Biophys Res Commun. 2019;508:339-47.

40. Wu K, Zhang N, Ma J, Huang J, Chen J, Wang L, Zhang J. Long noncoding RNA FAL1 promotes proliferation and inhibits apoptosis of human colon cancer cells. IUBMB Life. 2018;70:1093-100.

41. Yang L, Cui J, Wang Y, Tan J. FAM83H-AS1 is upregulated and predicts poor prognosis in colon cancer. Biomed Pharmacother. 2019;118:109342.

42. Yue B, Sun B, Liu C, Zhao S, Zhang D, Yu F, Yan D. Long non-coding RNA Fer-1-like protein 4 suppresses oncogenesis and exhibits prognostic value by associating with miR-106a-5p in colon cancer. Cancer Sci. 2015;106: 1323-32.

43. Matsumura K, Kawasaki Y, Miyamoto M, Kamoshida Y, Nakamura J, Negishi L, Suda S, Akiyama T. The novel G-quadruplex-containing long non-coding RNA GSEC antagonizes DHX36 and modulates colon cancer cell migration. Oncogene. 2017;36:1191-9.

44. Fang C, Qiu S, Sun F, Li W, Wang Z, Yue B, Wu X, Yan D. Long non-coding RNA HNF1A-AS1 mediated repression of miR-34a/SIRT1/p53 feedback loop promotes the metastatic progression of colon cancer by functioning as a competing endogenous RNA. Cancer Lett. 2017:410:50-62.

45. Luo ZF, Zhao D, Li XQ, Cui YX, Ma N, Lu CX, Liu MY, Zhou Y. Clinical significance of HOTAIR expression in colon cancer. World J Gastroenterol. 2016;22:5254-9.

46. Wu ZH, Wang XL, Tang HM, Jiang T, Chen J, Lu S, Qiu GQ, Peng ZH, Yan DW. Long non-coding RNA HOTAIR is a powerful predictor of metastasis and poor prognosis and is associated with epithelial-Mesenchymal transition in Colon Cancer. Oncol Rep. 2014;32:395-402.

47. Tatangelo F, Di Mauro A, Scognamiglio G, Aquino G, Lettiero A, Delrio P, Avallone A, Cantile M, Botti G. Posterior HOX genes and HOTAIR expression in the proximal and distal colon cancer pathogenesis. J Transl Med. 2018;16: 350.

48. Dong Y, Wei MH, Lu JG, Bi CY. Long non-coding RNA HULC interacts with miR-613 to regulate colon cancer growth and metastasis through targeting RTKN. Biomed Pharmacother. 2019;109:2035-42.

49. Yang Q, Wang $X$, Tang C, Chen X, He J. H19 promotes the migration and invasion of colon cancer by sponging miR-138 to upregulate the expression of HMGA1. Int J Oncol. 2017:50:1801-9.

50. Chen S, Bu D, Ma Y, Zhu J, Chen G, Sun L, Zuo S, Li T, Pan Y, Wang X, et al. $\mathrm{H} 19$ overexpression induces resistance to $1,25(\mathrm{OH}) 2 \mathrm{D} 3$ by targeting VDR through miR-675-5p in Colon Cancer cells. Neoplasia. 2017;19:226-36.

51. Zinovieva OL, Grineva EN, Prokofjeva MM, Karpov DS, Zheltukhin AO, Krasnov GS, Snezhkina AV, Kudryavtseva AV, Chumakov PM, Mashkova TD, et al. Expression of long non-coding RNA LINC00973 is consistently increased upon treatment of colon cancer cells with different chemotherapeutic drugs. Biochimie. 2018;151:67-72.

52. Guo K, Gong W, Wang Q, Gu G, Zheng T, Li Y, Li W, Fang M, Xie H, Yue C, et al. LINC01106 drives colorectal cancer growth and stemness through a positive feedback loop to regulate the Gli family factors. Cell Death Dis. 2020;11:869

53. Lin C, Zhang Y, Chen Y, Bai Y, Zhang Y. Long noncoding RNA LINC01234 promotes serine hydroxymethyltransferase 2 expression and proliferation by competitively binding miR-642a-5p in colon cancer. Cell Death Dis. 2019;10:137.

54. Yu X, Mi L, Dong J, Zou J. Long intergenic non-protein-coding RNA 1567 (LINC01567) acts as a "sponge" against microRNA-93 in regulating the proliferation and tumorigenesis of human colon cancer stem cells. BMC Cancer. 2017;17:716.
55. Wang ZK, Yang L, Wu LL, Mao H, Zhou YH, Zhang PF, Dai GH. Long noncoding RNA LINC00261 sensitizes human colon cancer cells to cisplatin therapy. Braz J Med Biol Res. 2017;51:e6793.

56. Lei Y, Wang YH, Wang XF, Bai J. LINC00657 promotes the development of colon cancer by activating PI3K AKT pathway. Eur Rev Med Pharmacol Sci. 2018;22:6315-23.

57. Liu J, Zhan Y, Wang J, Guo J, Kong D. Long noncoding RNA LINC01578 drives colon cancer metastasis through a positive feedback loop with the NF-kappaB/YY1 axis. Mol Oncol. 2020. https://doi.org/10.1002/1878-0261. 12819. Online ahead of print.

58. Tian J, Cui P, Li Y, Yao X, Wu X, Wang Z, Li C. LINC02418 promotes colon cancer progression by suppressing apoptosis via interaction with miR-34b5p/BCL2 axis. Cancer Cell Int. 2020;20:460.

59. Wang L, Bu P, Ai Y, Srinivasan T, Chen HJ, Xiang K, Lipkin SM, Shen X. A long non-coding RNA targets microRNA miR-34a to regulate colon cancer stem cell asymmetric division. Elife. 2016;5:e14620.

60. Liu Q, Huang J, Zhou N, Zhang Z, Zhang A, Lu Z, Wu F, Mo YY. LncRNA loc285194 is a p53-regulated tumor suppressor. Nucleic Acids Res. 2013;41: 4976-87.

61. Wang JH, Lu TJ, Kung ML, Yang YF, Yeh CY, Tu YT, Chen WS, Tsai KW. The long noncoding RNA LOC441461 (STX17-AS1) modulates colorectal Cancer cell growth and motility. Cancers. 2020;12(11):E3171. https://doi.org/10.3390/ cancers12113171.

62. Tian W, Du Y, Ma Y, Gu L, Zhou J, Deng D. MALAT1-miR663a negative feedback loop in colon cancer cell functions through direct miRNA-IncRNA binding. Cell Death Dis. 2018;9:857.

63. Wu Q, Meng WY, Jie $Y$, Zhao H. LncRNA MALAT1 induces colon cancer development by regulating miR-129-5p/HMGB1 axis. J Cell Physiol. 2018; 233:6750-7.

64. Kwok ZH, Roche V, Chew XH, Fadieieva A, Tay Y. A non-canonical tumor suppressive role for the long non-coding RNA MALAT1 in colon and breast cancers. Int J Cancer. 2018;143:668-78.

65. Kawasaki Y, Komiya M, Matsumura K, Negishi L, Suda S, Okuno M, Yokota N, Osada T, Nagashima T, Hiyoshi M, et al. MYU, a target IncRNA for Wnt/c-Myc signaling, mediates induction of CDK6 to promote cell cycle progression. Cell Rep. 2016:16:2554-64.

66. Marin-Bejar O, Marchese FP, Athie A, Sanchez Y, Gonzalez J, Segura V, Huang L, Moreno I, Navarro A, Monzo M, et al. Pint lincRNA connects the p53 pathway with epigenetic silencing by the Polycomb repressive complex 2. Genome Biol. 2013;14:R104.

67. Yu X, Zhao J, He Y. Long non-coding RNA PVT1 functions as an oncogene in human colon cancer through miR-30d-5p/RUNX2 axis. J buon. 2018;23: 48-54.

68. Zhang R, Li J, Yan X, Jin K, Li W, Liu X, Zhao J, Shang W, Liu Y. Long noncoding RNA Plasmacytoma variant translocation 1 (PVT1) promotes Colon Cancer progression via endogenous sponging miR-26b. Med Sci Monit. 2018:24:8685-92

69. Di Cecilia S, Zhang F, Sancho A, Li S, Aguilo F, Sun Y, Rengasamy M, Zhang W, Del Vecchio L, Salvatore F, Walsh MJ. RBM5-AS1 is critical for self-renewal of Colon Cancer stem-like cells. Cancer Res. 2016;76:5615-27.

70. Zhou P, Sun L, Liu D, Liu C, Sun L. Long non-coding RNA lincRNA-ROR promotes the progression of Colon Cancer and holds prognostic value by associating with miR-145. Pathol Oncol Res. 2016;22:733-40.

71. Zhang XW, Li SL, Zhang D, Sun XL, Zhai HJ. RP11619L19.2 promotes colon cancer development by regulating the miR12715p/CD164 axis. Oncol Rep. 2020;44(6):2419-28.

72. Lee H, Kim C, Ku JL, Kim W, Yoon SK, Kuh HJ, Lee JH, Nam SW, Lee EK. A long non-coding RNA snaR contributes to 5-fluorouracil resistance in human colon cancer cells. Mol Cell. 2014;37:540-6.

73. Zhou HB, Li Q, Liu M, Cao YQ, Xu JY. Increased expression of long noncoding RNA SBDSP1 correlates with poor survival in colorectal cancer. Eur Rev Med Pharmacol Sci. 2017;21:3837-41.

74. Shi D, Liang L, Zheng $H$, Cai G, Li X, Xu Y, Cai S. Silencing of long noncoding RNA SBDSP1 suppresses tumor growth and invasion in colorectal cancer. Biomed Pharmacother. 2017;85:355-61.

75. Yang $H$, Wang $S$, Kang $Y J$, Wang $C, X u Y$, Zhang $Y$, Jiang Z. Long noncoding RNA SNHG1 predicts a poor prognosis and promotes colon cancer tumorigenesis. Oncol Rep. 2018;40:261-71.

76. Liu KL, Wu J, Li WK, Li NS, Li Q, Lao YQ. LnCRNA SNHG7 is an oncogenic biomarker interacting with MicroRNA-193b in Colon carcinogenesis. Clin Lab. 2019;65(11). https://doi.org/10.7754/Clin.Lab.2019.190501. 
77. Jiang H, Li T, Qu Y, Wang X, Li B, Song J, Sun X, Tang Y, Wan J, Yu Y, et al. Long non-coding RNA SNHG15 interacts with and stabilizes transcription factor slug and promotes colon cancer progression. Cancer Lett. 2018;425: 78-87.

78. Liu J, Zhan Y, Wang J, Guo J, Kong D. IncRNA-SNHG17 promotes colon adenocarcinoma progression and serves as a sponge for miR-375 to regulate CBX3 expression. Am J Transl Res. 2020;12:5283-95.

79. Zhai HY, Sui MH, Yu X, Qu Z, Hu JC, Sun HQ, Zheng HT, Zhou K, Jiang LX. Overexpression of long non-coding RNA TUG1 promotes Colon Cancer progression. Med Sci Monit. 2016;22:3281-7.

80. Taniue K, Kurimoto A, Sugimasa H, Nasu E, Takeda Y, Iwasaki K, Nagashima T, Okada-Hatakeyama M, Oyama M, Kozuka-Hata H, et al. Long noncoding RNA UPAT promotes colon tumorigenesis by inhibiting degradation of UHRF1. Proc Natl Acad Sci U S A. 2016;113:1273-8.

81. Li D, Bao J, Yao J, Li J. IncRNA USP2-AS1 promotes colon cancer progression by modulating hippo/YAP1 signaling. Am J Transl Res. 2020;12:5670-82.

82. Sun N, Zhang G, Liu Y. Long non-coding RNA XIST sponges miR-34a to promotes colon cancer progression via Wnt/beta-catenin signaling pathway. Gene. 2018;665:141-8.

83. Fang C, Zan J, Yue B, Liu C, He C, Yan D. Long non-coding ribonucleic acid zinc finger antisense 1 promotes the progression of colonic cancer by modulating ZEB1 expression. J Gastroenterol Hepatol. 2017;32:1204-11.

84. Zhao B, Qu X, Lv X, Wang Q, Bian D, Yang F, Zhao X, Ji Z, Ni J, Fu Y, et al. Construction and characterization of a synergistic IncRNA-miRNA network reveals a crucial and prognostic role of IncRNAs in Colon Cancer. Front Genet. 2020;11:572983

85. Wang K, Zhang M, Wang C, Ning X. Long noncoding RNA LINC01296 harbors miR-21a to regulate Colon carcinoma proliferation and invasion. Oncol Res. 2019;27:541-9.

86. Jones PA. Functions of DNA methylation: islands, start sites, gene bodies and beyond. Nat Rev Genet. 2012;13:484-92.

87. Zheng X, Chen L, Zhou Y, Wang Q, Zheng Z, Xu B, Wu C, Zhou Q, Hu W, Wu C, Jiang J. A novel protein encoded by a circular RNA circPPP1R12A promotes tumor pathogenesis and metastasis of colon cancer via hippoYAP signaling. Mol Cancer. 2019;18:47.

88. Zhang Q, Zhang C, Ma JX, Ren H, Sun Y, Xu JZ. Circular RNA PIP5K1A promotes colon cancer development through inhibiting miR-1273a. World J Gastroenterol. 2019;25:5300-9.

89. Zhan W, Liao X, Wang Y, Li L, Li J, Chen Z, Tian T, He J. circCTIC1 promotes the self-renewal of colon TICs through BPTF-dependent c-Myc expression. Carcinogenesis. 2019;40:560-8.

90. Wang L, Peng X, Lu X, Wei Q, Chen M, Liu L. Inhibition of hsa_circ_0001313 (circCCDC66) induction enhances the radio-sensitivity of colon cancer cells via tumor suppressor miR-338-3p: effects of cicr_0001313 on colon cancer radio-sensitivity. Pathol Res Pract. 2019;215:689-96.

91. Min L, Wang H, Zeng Y. CircRNA_104916 regulates migration, apoptosis and epithelial-mesenchymal transition in colon cancer cells. Front Biosci (Landmark Ed). 2019;24:819-32.

92. He JH, Li YG, Han ZP, Zhou JB, Chen WM, Lv YB, He ML, Zuo JD, Zheng L. The CircRNA-ACAP2/Hsa-miR-21-5p/ Tiam1 regulatory feedback circuit affects the proliferation, migration, and invasion of Colon Cancer SW480 cells. Cell Physiol Biochem. 2018;49:1539-50.

93. Lin J, Cai D, Li W, Yu T, Mao H, Jiang S, Xiao B. Plasma circular RNA pane acts as a novel diagnostic biomarker for colorectal cancer. Clin Biochem. 2019;74:60-8

94. Li J, Qi Y. Ginsenoside Rg3 inhibits cell growth, migration and invasion in Caco-2 cells by downregulation of IncRNA CCAT1. Exp Mol Pathol. 2019;106: $131-8$.

95. Zinovieva OL, Grineva EN, Prokofjeva MM, Karpov DS, Krasnov GS, Prassolov VS, Mashkova TD, Lisitsyn NA. Treatment with anti-cancer agents results in profound changes in IncRNA expression in colon cancer cells. Mol Biol. 2017:51:841-8

96. Gharib E, Nazemalhosseini-Mojarad E, Baghdar K, Nayeri Z, Sadeghi H, Rezasoltani S, Jamshidi-Fard A, Larki P, Sadeghi A, Hashemi M, Asadzadeh Aghdaei H. Identification of a stool long non-coding RNAs panel as a potential biomarker for early detection of colorectal cancer. J Clin Lab Anal. 2020:e23601. https://doi.org/10.1002/jcla.23601.

\section{Publisher's Note}

Springer Nature remains neutral with regard to jurisdictional claims in published maps and institutional affiliations.

\section{Ready to submit your research? Choose BMC and benefit from}

- fast, convenient online submission

- thorough peer review by experienced researchers in your field

- rapid publication on acceptance

- support for research data, including large and complex data types

- gold Open Access which fosters wider collaboration and increased citations

- maximum visibility for your research: over $100 \mathrm{M}$ website views per year

At BMC, research is always in progress.

Learn more biomedcentral.com/submissions 